\title{
Olive oil and immune system functions: potential involvement in immunonutrition
}

\author{
By Manuel A. de Pablo*, María A. Puertollano and Gerardo Álvarez de Cienfuegos
}

Unit of Microbiology, Department of Health Sciences, Faculty of Experimental Sciences,
University of Jaén, Jaén, Spain

"Corresponding author: : Dr. Manuel A. de Pablo. Tel: +34 953012003

Email: mapablo@ujaen.es

\section{CONTENTS}

1. INTRODUCTION

2. IMMUNE SYSTEM: INNATE (NATURAL) AND ACQUIRED (ADAPTIVE) IMMUNITY

3. MECHANISMS INVOLVED IN THE MODULATION OF IMMUNE SYSTEM BY DIETARY LIPIDS

4. BIOLOGICAL CONSEQUENCES: ALTERATION OF IMMUNE SYSTEM FUNCTIONS BY DIETARY LIPIDS. PARTICULAR RELEVANCE OF OLIVE OIL

4.1. Lymphocyte proliferation

4.2. Cytokine production

4.3. Natural killer cell activity

4.4. Adhesion molecules

5. CLINICAL CONSEQUENCES: APPLICATION OF OLIVE OIL IN IMMUNONUTRITION

5.1. Inflammatory disorders

5.2. Resistance to infectious agents

6. CLINICAL NUTRITION AND IMMUNE SYSTEM

7. OPEN QUESTIONS AND FUTURE PERSPECTIVES ACKNOWLEDGMENTS

REFERENCES

\section{RESUMEN}

Aceite de oliva y funciones del sistema inmune: papel potencial en la inmunonutrición.

El aceite de oliva tiene un papel crucial como componente de la dieta Mediterránea, con importantes beneficios sobre la salud humana. Dietas conteniendo aceite de oliva actúan de manera favorable en las funciones del sistema inmune por la acción sobretodo del ácido oleico. Los estudios epidemiológicos, clínicos y experimentales publicados en los últimos años demuestran que ciertos lípidos de la dieta [ácidos grasos monoinsaturados (MUFA) y poliinsaturados (PUFA)] pueden modular (suprimir) distintas funciones del sistema inmune, tanto en humanos como en animales. Grasas ricas en MUFA y PUFA se han utilizado para reducir los síntomas de enfermedades caracterizadas por una sobreactivación del sistema inmune (enfermedades autoinmunes) y el riesgo de cáncer. En este capítulo se revisan los datos clínicos y experimentales asociados con los efectos saludables del aceite de oliva, en particular aquellos relacionados con el sistema inmune y los mecanismos de acción. Además, se discuten los efectos adversos sobre las funciones del sistema inmune de ciertos lípidos de la dieta, que pueden atribuirse a una reducción de la resistencia natural del hospedador contra microorganismos infecciosos, indicando el papel del aceite de oliva en la regulación de estos procesos.

PALABRAS-CLAVE: Aceite de oliva; Sistema inmune; Linfocitos; Citoquinas; Enfermedades autoinmunes; Infección; Resistencia inmunológica.

\section{SUMMARY}

Olive oil and immune system functions: potential involvement in immunonutrition.

Olive oil plays a crucial role as a main component of the Mediterranean diet, which has shown important benefits for the human health. According to the current knowledge, the administration of diets containing olive oil exerts some beneficial effects on the immune system functions due likely to the action of oleic acid rather than other substances contained in this fat. In the last few years, epidemiological, clinical and experimental studies have evidenced the potential of certain dietary lipids (containing polyunsaturated or monounsaturated fatty acids) as modulators of immune system functions due to their ability to suppress several functions of immune system in both humans and animals. As a result, these fats have been applied in the reduction of symptoms from diseases characterized by an overactivation of the immune system (autoimmune diseases) or in the reduction of cancer risk. Here, we review several relevant experimental and clinical data associated with the beneficial effects of olive oil upon the health, the mechanisms of action and the immune function susceptible of being be altered by the administration of dietary lipids and particularly of olive oil. In addition, we will also discuss the detrimental effects on the immune system functions caused by the administration of certain dietary lipids attributed mainly to a reduction of host natural resistance against infectious microorganisms as well as the involvement of olive oil diets in the regulation of immune resistance.

KEY-WORDS: Olive oil, Immune system, Lymphocytes, Cytokines, Autoimmune diseases, Infection, Immune resistance.

\section{INTRODUCTION}

Evidence from both epidemiological and experimental studies reflects the interaction between nutrition and the immune system (Klasing and Leihchinsky, 2000). One of the best examples supporting this argument is based on the fundamental role that different types of fatty acids [mainly long chain $n-3$ or $n-6$ polyunsaturated fatty acids (PUFA)] play in the regulation of immune system functions, which acquire a great importance in human immunonutrition. Nevertheless, olive oil (a main component of the Mediterranean diet) also plays a crucial role in the modulation of immune system. Indeed, the intake of Mediterranean diet has recently been associated with an important reduction 
of mortality in a Greek population, which increases the importance of olive oil as a fundamental constituent of this diet (Trichopoulou, 2003).

In addition to PUFA, olive oil has also been related to the suppression of different immune system functions. Overall, the action of these dietary fatty acids on the immune system of humans has allowed their application in the resolution or attenuation of diseases characterized by inflammatory disorders, such as rheumatoid arthritis (Kremer, 1990; Linos, 1991; Linos, 1999) and in the reduction ( $n-3$ or $n-9$ fatty acids) or promotion ( $n-6$ fatty acids) of cancer risk (Caygill, 1996; Martin-Moreno, 1994; Risio, 1996; Trichopoulou, 1995).

Over the past two decades, many studies have demonstrated the mechanisms of action by which several fatty acids contained in the diets are capable of modulating the immune system in both humans and animals (reviewed in Calder, 1998; de Pablo, 2000c; de Pablo and Alvarez de Cienfuegos, 2000). The proposed mechanisms will be explained in the present review as well as the immunological functions susceptible of being modulated by dietary lipids and particularly by olive oil.

At the beginning, the epidemiological studies contributed to demonstrate that certain fatty acids supplied in the diets (particularly $n$-3 PUFA contained in marine fish oil) affect the immune response of Greenland Eskimos. There is a low prevalence of inflammatory disorders in this population (Kromann and Green, 1980), a reduction of death from ischemic heart disease despite the administration of diets high in fat and cholesterol (Bang, 1980; Kromhout, 1989), and a low prevalence of cancer (Blot, 1975). Subsequently, numerous experimental and clinical investigations have examined the protective role of long-chain $n-3$ PUFA against inflammatory disorders (Harbige, 1998), cardiovascular diseases (Connor and Connor, 1997) and cancer development (Rose and Connolly, 1999). Despite their beneficial effects in the reduction of inflammatory disorders, other studies have demonstrated that the administration of diets containing long-chain $n-3$ PUFA may contribute, at least in part, to reducing host resistance against infectious diseases. Indeed, epidemiological investigations described a high incidence of tuberculosis in native Eskimos (Kaplan, 1972), who consume a great amount of $n-3$ PUFA. These data are illustrative of the potential action of certain fatty acids and of the consequences derived from an excessive suppression of immune functions.

On the other hand, few experimental studies have examined the essential contribution of olive oil in the modulation of immune system, and most current knowledge is based on epidemiological data. Therefore, it is important to answer several questions

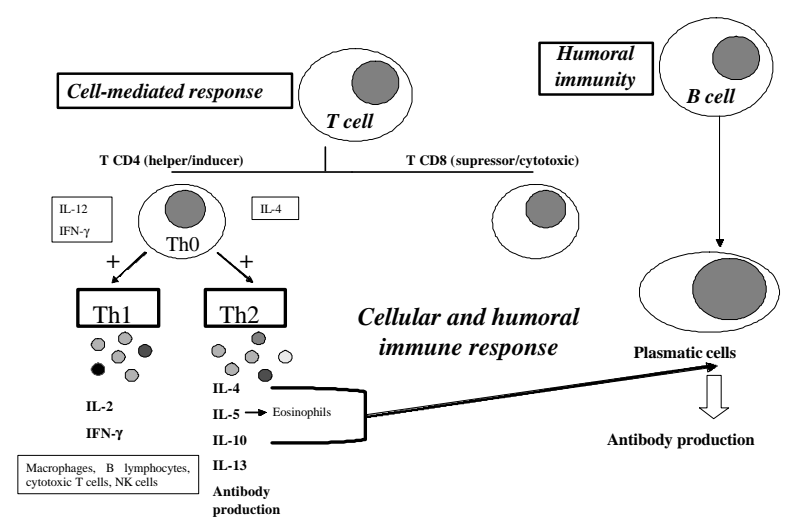

Figure 1

Schematic representation of cell mediated and humoral immunity. $\mathrm{IL}=$ interleukin; IFN=interferon; $\mathrm{NK}=$ natural killer.

related to this topic: does the olive oil exert immunosuppressive functions similar to fish oil?, what are the advantages or disadvantages derived from the modulation of immune system by different fatty acids?.

Before describing the potential role on the immune system of certain fatty acids of the diet, especially olive oil, it is essential to define the concept of immunity as well as the functional division of immune system. Briefly, immunity may be defined as a state of resistance and protection against biological agents (such as viruses, bacteria, fungi or parasites) that allows the elimination and the destruction of these infectious agents.

Therefore, the immune system is an integrated defence network that comprises two separate but interacting and interdependent types (Figure 1): (i) the innate, natural or non-specific immune system, and (ii) the acquired, adaptive or specific immune system. Both components of immunity involve the production and release of different factors and the recruitment of various types of cells (leukocytes) which are originated in bone marrow. These cells circulate in the bloodstream or organized into lymphoid organs. They are divided into two broad groups: phagocytes (macrophages/monocytes, eosinophils, neutrophils and basophils) and lymphocytes [ $\mathrm{T}$ lymphocytes, B lymphocytes and natural killer cells (NK)]. Similarly, T lymphocytes can be divided into two fundamental groups: on the one hand, Th1 lymphocytes, which are regulated by interleukin-12 (IL-12) and interferon- $\gamma$ (IFN- $\gamma$ ), produce pro-inflammatory cytokines (such as IL-2 or IFN- $\gamma$ ) and activate macrophages, NK cells and cytotoxic T lymphocytes; on the other hand, Th2 lymphocytes which are regulated by IL-4 are specialized in the production of cytokines with an anti-inflammatory activity (such as IL-4, IL-5 or IL-10). Hence, infection with intracellular pathogens will induce the differentiation along the Th1 pathway, 
whereas infection with extracellular pathogens will promote the differentiation along the Th2 pathway.

This review summarizes the current state of knowledge concerning the effects and interactions of olive oil on immune system functions. Hence, we propose to examine epidemiological, experimental and clinical data that reveal a potential involvement of olive oil or oleic acid (the main fatty acid contained in olive oil) on the immune system functions in animals and humans as well as the beneficial effects of olive oil in the reduction of inflammatory diseases. In addition, we will review the adverse properties of certain unsaturated fatty acids in the reduction of the resistance against infectious agents due to an immunosuppressive effect.

\section{IMMUNE SYSTEM: INNATE (NATURAL) AND ACQUIRED (ADAPTIVE) IMMUNITY}

The immune system consists of a complex network of cells and factors responsible for the protection of the host from infectious agents. Hence, immune system should recognise the self from non-self and to eliminate non-self, which constitutes a critical function of this system.

The innate arm of immunity prevents the entry of infectious agents into the body. It plays a crucial role in the early control of pathogenic infectious agents as well as in the initiation and subsequent course of the acquired immunity. Therefore, it constitutes the first line (early phase) of defence against pathogens. On the basis of this preliminary concept, innate immunity represents an important mechanism which rapidly eliminates infectious agents through different mechanisms such as phagocytosis or engulfment of infectious agents, direct destruction by the production of complement or toxic substances released from phagocytic cells or NK cells. In fact, innate immunity is the most efficient mechanism in order to eliminate intracellular growth pathogenic agents. Innate resistance does not distinguish among microorganisms and does not change in intensity upon re-exposure.

On the other hand, acquired immunity requires the identification of molecules from an invading agent. The recognition of antigens is carried out by $\mathrm{B}$ lymphocytes and $\mathrm{T}$ lymphocytes, which produce antibodies and recognize the antigens on the surface of cells, respectively. Intracellular infections are communicated to T lymphocytes by the expression of peptide fragments along with proteins of the major histocompatibility complex (MHC). Thus, maturation and expansion of $\mathrm{T}$ lymphocytes is an essential process for destroying invading organisms. The link of peptide (antigen) and MHC is identified by $\mathrm{T}$ lymphocytes. There are two types of MHC molecules: MHC class I and MHC class II. MHC I binds intracellular peptides (from viruses or intracellular growth bacteria), and it is subsequently recognized by $T$ lymphocytes expressing CD8 receptor (cytotoxic/suppressor T lymphocytes) which leads to the destruction of the infected cell. MHC II binds peptides from foreign agents that have been phagocytosed by macrophages or by antigen-presenting cells (extracellular antigens) and it is recognized by $\mathrm{T}$ lymphocytes expressing CD4 receptor (helper/inducer T lymphocytes) which leads to activating T cell-mediated response. Finally, both innate and acquired immune responses are integrated through the interactions of cells and cytokine production generated as a result of a specific stimulus. Thus, the infectious agent is eliminated and immunological memory remains; therefore, the response of the immune system against a second response by a similar antigen is more rapid (Abbas, 2001). Differential properties of both innate and acquired immune system are summarized in Table 1.

\section{MECHANISMS INVOLVED IN THE MODULATION OF IMMUNE SYSTEM BY DIETARY LIPIDS}

Over the past few years major advances have been made in our understanding of the specific mechanisms which contribute to regulating the immune system through the action of dietary lipids. In fact, it is generally assumed that the most immunosuppressive fat is fish oil [containing long chain $n-3$ PUFA such as eicosapentaenoic acid (EPA, 20:5n-3) and docosahexaenoic acid (DHA, 22:6n-3)], which have been extensively studied since the early 1970s. However, several investigations have included in their protocols diets containing $n-6$ PUFA (from sunflower, soybean or maize oils) or diets containing olive oil rich $n-9$ monounsaturated fatty acids (MUFA) such as oleic acid. In general, $n-3$ fatty acids have been proposed as substances that contribute to suppressing the immune function, whereas $n-6$ fatty acids enhance the activity of the immune system (Miles and Calder, 1998). Nevertheless, several lines of evidence have demonstrated that olive oil also exerts an immunosuppressor effect when it is administered in animal diets (Yaqoob, 1994a). Hence, different modes of action have been proposed in order to explain the mechanisms that participate in the modulation of immune system functions by the fatty acids of the diet. Thus, dietary lipid manipulation can involve one or more of the following mechanism: alteration of plasma membrane fluidity, eicosanoid production, modification of oxidative stress or alteration of nuclear transcription factors. In addition, programmed cell death or apoptosis has recently been proposed as another mechanism capable of being promoted or inhibited by fatty acids of the diet, which may be partially responsible for the modulation of immune system functions. 
Table 1

Factors that participate in innate and acquired immunity

\begin{tabular}{lll}
\hline & & \multicolumn{1}{c}{ Immune system } \\
\hline Factors & Innate Immunity & Acquired Immunity \\
\hline Specificity & Nonspecific & Specific \\
Physicochemicals & Skin & Antibodies in mucosa \\
& Acid in the stomach & \\
& Sebaceous gland secretions & \\
& Lysozime & \\
& Natural microbiota & \\
Cells & Monocytes/macrophages & Lymphocytes (T and B cells) \\
& Polymorphonuclear cells & \\
& Natural killer cells & \\
Cytokines & Complement & Antibodies \\
& Macrophage-derived cytokines & Lymphocyte-derived cytokines \\
& &
\end{tabular}

Cell culture experiments have demonstrated that changes in fatty acid composition of lymphocytes do alter membrane fluidity (Calder, 1994). Alteration of plasma membrane fluidity is caused by changes in the type of phospholipids as a direct consequence of the incorporation of dietary lipids. Hence, changes in fluidity may modify the binding of cytokines and cytokine-inducing agonists to receptors (Stubbs and Smith, 1984). As a consequence, numerous cellular functions may be regulated, such as expression of MHC class II molecules or intercellular adhesion molecule-1 (ICAM-1), which lead to an inhibition in the antigen-presenting function, responsible at least in part, for the suppression of cell-mediated immune response (Hughes and Pinder, 2000).

PUFA are more sensitive to lipid peroxidation than are MUFA or saturated fatty acids (SFA). The incorporation of PUFA into plasma membrane increases lipid peroxidation. This fact may affect expression of surface molecules due mainly to the production of free radicals. It is generally known that (extra virgin) olive oil contains oleic and other fatty acids, but also is particularly rich in phenolic compounds. They exhibit antioxidant activity and seem to exert a considerable protection against colon or breast cancer due mainly to the inhibition of oxidative stress (Owen, 2000; Filik and Ozyilkan, 2003; and as reviewed in issue 4).
Eicosanoids are lipid mediators that regulate an important number of inflammatory effects. The administration of different fatty acids alters the eicosanoids production. In general, eicosanoids derived from $n-3$ PUFA are less potent than eicosanoids derived from $n-6$ PUFA (Shapiro, 1993). Therefore, the alteration of arachidonic acid $(20: 4 n-6)$ availability as a substrate alters the capability of cells to produce eicosanoids. This event modifies a wide range of cell responses.

A great number of cell-signalling molecules are originated from membrane phospholipids (diglycerides, ceramide, inositol triphosphate) which regulate the activities of some proteins related to the mechanism of cell signalling. Hence, the alteration of phospholipids fatty acid composition produces changes in the affinity of these substances as substrates for the enzymes responsible for the generation of signalling molecules (Jump and Clarke, 1999).

Supplementation of human colon adenocarcinoma cell lines with fish oil or olive oil led to an early down-regulation of cyclooxygenase-2 (COX-2), which is related to an inhibition of apoptosis (Lipkin, 1999), and a reduction of Bcl-2 expression, which explains the induction of apoptosis and cell differentiation and their importance in the prevention of colorectal carcinogenesis (Llor, 2003). Future 
studies will determine the participation of several fatty acids such as oleic acid in the modulation of mechanisms that lead to apoptosis.

\section{BIOLOGICAL CONSEQUENCES: ALTERATION OF IMMUNE SYSTEM FUNCTIONS BY DIETARY LIPIDS. PARTICULAR RELEVANCE OF OLIVE OIL}

\subsection{Lymphocyte proliferation}

Most studies investigating the effects of fatty acids on the immune system have demonstrated that a diet containing olive oil administered to animals promotes a significant reduction of lymphocyte proliferation in response to the mitogen concanavalin A (Con A) (Yaqoob, 1994a). At a first glance, olive oil is composed by different types of substances, and therefore anyone of them may be associated to the suppression of lymphocyte proliferation. Based on this hypothesis, an interesting study examined the biological component of olive oil responsible for this suppression, because olive oil contains sterols, alcohols and antioxidants apart from oleic acid and other (apparently) less relevant fatty acids. This investigation revealed that the immunosuppressive effects of olive oil are likely due to oleic acid rather than to other components of this fat (Jeffery, 1997b). However, this aspect is not fully demonstrated. By contrast, human studies have produced conflicting results, because a diet rich in olive oil does not affect proliferation of mitogen-stimulated leukocytes (Yaqoob, 1998). It is possible that these differences between animals and humans response might be attributed to the amount of monounsaturated fat employed in the animal studies, where diets contributed approximately $30 \%$ of total energy, whereas in human studies diets supplied approximately $18 \%$ of total energy intake (Yaqoob, 2002). Although the mentioned studies demonstrated a significant reduction of lymphocyte proliferation in animals, we did not find significant differences in the proliferation of lymphocytes from animals fed with a diet containing olive oil and stimulated with Con A (which induces proliferation of T lymphocytes) or lipopolysaccharide (LPS) (which induces proliferation of $\mathrm{B}$ lymphocytes) (Puertollano, 2002). The specific factors that contribute to the contradictory results observed in both animals and humans should be elucidated in further studies. However, other factors different of the amount of olive oil in the diet, such as ingestion of other nutrients, could be involved in the different results observed between animals and humans.

\subsection{Cytokine production}

Cytokine production is reduced by the administration of certain dietary lipids. In general, cytokines may be divided into lymphokines and monokines. The first one are involved in specific immunity and produced by $\mathrm{T}$ cells in an activation state. These proteins regulate the growth and differentiation of different lymphocyte subsets and they activate and regulate cells that participate in the inflammatory response. Interleukin-2 (IL-2) is an important cytokine responsible for the proliferation of $\mathrm{T}$ lymphocytes. Administration of diets containing olive oil for 8 or 12 weeks produced an increase of IL-2 production (Yaqoob and Calder, 1995a; de Pablo, 1998a). IL-4 is another cytokine with anti-inflammatory functions; the production of this cytokine is increased in animals after the administration for four weeks of a diet containing olive oil (unpublished results). By contrast, the production of IL-10, a cytokine with similar functions to IL-4, is decreased after the administration of a diet containing olive oil, but this reduction did not show significant differences in comparison with the production of IL-10 in animals fed a diet containing low fat (Yaqoob and Calder, 1995a). Finally, the synthesis of IL-12, a cytokine that participates as a pro-inflammatory protein, was reduced in animals fed with diets containing olive oil (unpublished results). As mentioned previously, monokines are the second type of cytokines that participates as inflammatory mediators, and they are produced mainly by monocytes/macrophages. The production of these proteins is also modulated by the administration of dietary lipids. Thus, IL-1 production is reduced, whereas IL- 6 or TNF- $\alpha$ production are substantially increased or not modified (Yaqoob and Calder, 1995b; de Pablo, 1998b). Nevertheless, the administration of fish oil diets is involved in the reduction of IL-1, IL-2, TNF- $\alpha$ or IFN- $\gamma$ (Yaqoob and Calder, 1995b). However, although olive oil diets are also related to the suppression of cytokine production, this effect is not as severe as that produced by the administration of fish oil.

\subsection{Natural killer cell activity}

Natural killer (NK) cell activity is another important natural immune function modulated by the action of certain dietary lipids. NK cells are a central lymphocyte subset found in blood and spleen that destroy virus-invaded cells or transformed cells. In animal studies, olive oil diet reduced the NK cell activity, although the most suppressive diet associated to an important reduction of NK cell activity from animals was that containing fish oil (Yaqoob, 1994b, Jeffery, 1996). In fact, NK cell activity was significantly reduced in animals fed with olive oil after receiving tumour transplantation LSTRA (mouse T cell lymphoma), although the greatest suppression was observed in animals fed 


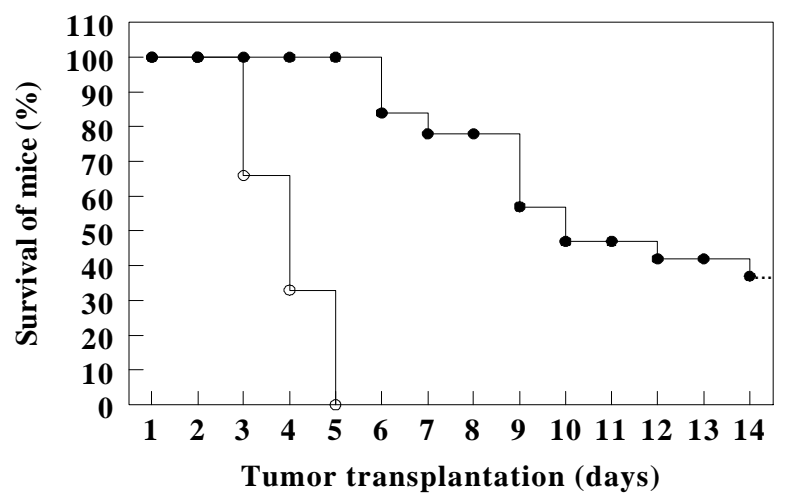

Figure 2

Measurement of survival percentage of mice fed with dietary lipids for four weeks. After the feeding period mice were transplanted with a murine lymphoma LSTRA. The figure represents the survival percentage of mice transplanted. Mice fed with a diet containing olive oil (OO, closed circles) and mice fed a diet containing fish oil (FO, open circles). This figure has been partially adapted from Puertollano (2001a).

with a fish oil diet (Puertollano, 2001a) (Figure 2). The comparison of different doses of oleic acid in the diet showed a negative linear relationship, indicating that oleic acid is responsible for a reduction of NK cell activity in animals (Jeffery, 1997a). Once again, human studies have not confirmed similar results, because the measurement of NK cell activity after the administration for one or two months of a diet containing olive oil did not show relevant differences, although the activity of these cells declined after two months of the incorporation of the mentioned diet (Yaqoob, 1998).

\subsection{Adhesion molecules}

An interesting line of investigation is based on the potential effect of dietary lipids on the expression of adhesion molecules. Thus, there was a decrease in the levels of expression of CD-2, lymphocyte function antigen-1 (LFA-1) and ICAM-1 on spleen lymphocytes from animals fed with diets containing olive oil or fish oil (Sanderson, 1995). Similarly, an olive oil diet reduced the levels of ICAM-1 after two months of dietary administration in humans (Yaqoob, 1998). These relevant studies have an important clinical interpretation, because ICAM-1 is an adhesion molecule involved in different functions. This molecule participates in leukocyte-leukocyte adhesion as well as in leukocyte-endothelial cells adhesion. This molecule is also expressed on mononuclear cells isolated from inflamed synovium in individuals suffering from rheumatoid arthritis. In addition, it also participates in the recruitment of mononuclear cells responsible for the formation and development of atherosclerotic plaque.

\section{CLINICAL CONSEQUENCES: APPLICATION OF OLIVE OIL IN IMMUNONUTRITION}

\subsection{Inflammatory disorders}

Epidemiological studies have demonstrated the efficiency of certain dietary lipids in the reduction of autoimmune diseases which are characterized by inflammatory disorders. It is clear that diets containing long-chain $n-3$ PUFA or $n-9$ MUFA modulate the immune system and therefore, it is obvious that the type of fatty acids supplied in the diet acquire a significant importance in clinical therapy to reduce the typical symptoms of this disease.

Evidence from intervention studies indicates that supplementation of the diet with fish oil or olive oil significantly improves the symptoms of rheumatoid arthritis due to a suppression of the immune response by altering the mediators participating in the immune response. An important study determined the effects of fish oil diet on the evolution and severity of rheumatoid arthritis (Kremer, 1990). Although the group fed a diet containing olive oil was used as control, a reduction of symptoms was detected after olive oil administration (Kremer, 1990). Therefore, olive oil shows a beneficial role in the reduction of inflammatory disorders. In fact, the risk of developing rheumatoid arthritis was four times smaller in a Greek population that had been administered olive oil than in the population consuming olive oil in a low frequency. This important epidemiological study suggests that olive oil improves the symptoms of rheumatoid arthritis by alteration of the production of inflammatory response mediators (Linos, 1991; Linos, 1999). The anti-inflammatory activity of oleic acid appears to be associated to the production of its metabolite eicosatrienoic acid (20:3n-9), which is a potent inhibitor of the leukotriene $\mathrm{B}_{4}$ synthesis. Therefore, the anti-inflammatory effects of oleic acid are exerted through a mechanism similar to that of fish oil, which contains 20:5n-3 (EPA) (James, 1993). It is probable that the beneficial effects of olive oil may be attributed, in part, to the presence of natural antioxidants, which contribute to increase the stability of the oil (Linos, 1999). However, the effects of olive oil on the immune system are associated to oleic acid rather than other minor components (Jeffery, 1997b).

\subsection{Resistance to infectious agents}

Several lines of evidence have demonstrated that the suppression of immune system functions generated by certain dietary lipids may cause a reduction of natural host resistance (reviewed in de Pablo, 2000b; de Pablo, 2002; Puertollano and de Pablo, 2002; Anderson and Fritsche, 2002). Obviously, available data only refer to animal 

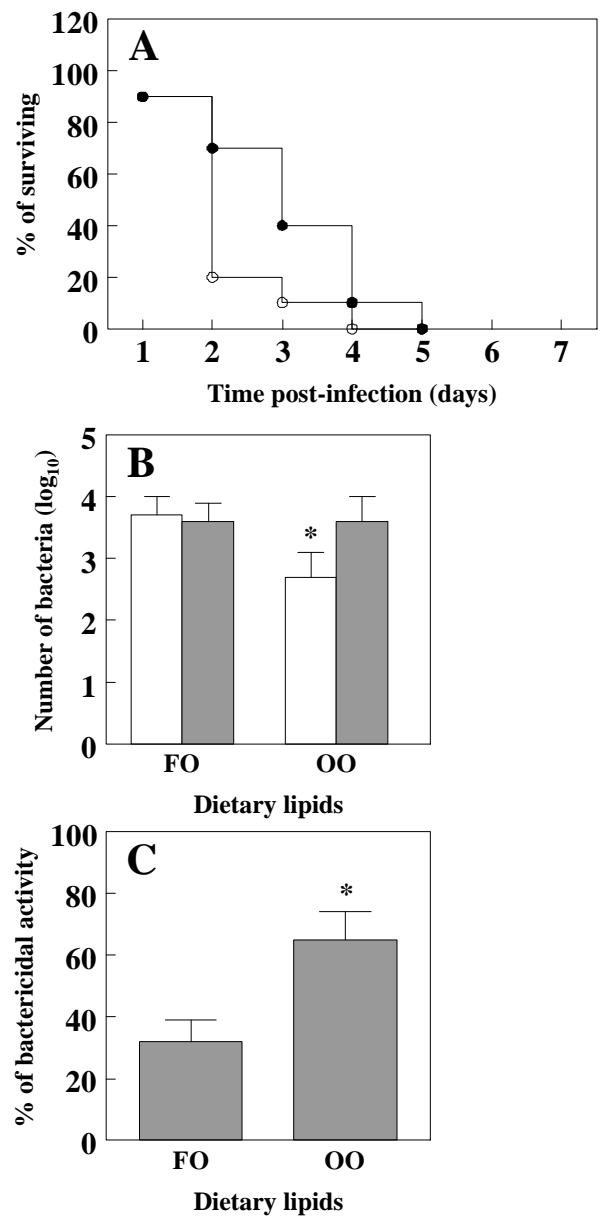

Figure 3

Measurement of survival percentage of mice, determination of number of bacteria from spleen and bactericidal activity in peritoneal cells from mice fed olive oil or fish oil for four weeks and experimentally infected with $L$. monocytogenes. A. Survival percentage of mice fed with diets containing fish

oil (FO, open circles) or olive oil (OO, closed circles). B. Number of viable bacteria from spleen of mice fed a FO diet and an $\mathrm{OO}$ diet after $48 \mathrm{~h}$ (open bars) and $96 \mathrm{~h}$ (closed bars) of infection. C. Measurement of bactericidal activity of peritoneal cells in mice fed diets containing FO or $\mathrm{OO}$. These figures

have been partially adapted from de Pablo (2000a); Puertollano (2001b). A value of ${ }^{*} p<0.05$ is considered as statistically significant.

experiments and the effect of dietary lipids on infectious resistance in healthy humans has not been elucidated yet.

Different epidemiological studies have reported that the administration of diets containing fish oil increases the risk and the incidence of tuberculosis in native Eskimos (Comstock, 1967; Kaplan, 1972). Subsequently, experimental studies have confirmed this argument, because the administration of diets containing long chain $n-3$ PUFA to animals infected with a virulent pathogen has demonstrated a significant reduction of survival percentage as well as an important increase of viable bacteria from spleen (de Pablo, 2000a) or liver (Fritsche, 1997). These data indicate that the suppression of immune system shown by these fatty acids leads to a relevant reduction of host resistance against infectious microorganisms (reviewed in de Pablo and Alvarez de Cienfuegos, 2000; de Pablo, 2002; de Pablo, 2000c; Anderson and Fritsche, 2002). Thus, the elimination of infectious agents is more difficult and their actions are more harmful.

Several studies have indicated the involvement of long-chain $n-3$ PUFA in the modulation of natural resistance against different infectious agents such as Salmonella typhimurium serovar Typhimurium (Chang, 1992), Mycobacterium tuberculosis (Paul, 1997), Listeria monocytogenes (Fritsche, 1997; de Pablo, 2000a), influenza virus (Byleveld, 2000; Byleveld, 1999), or parasites (Blok, 2002). Experimental infection with $L$. monocytogenes after administration of diets containing fish oil has reduced the percentage of animals' survival indicating a suppression of resistance due to dietary lipid administration (de Pablo, 2000a; Fritsche, 1997). Olive oil administration did not reduce the percentage of survival to an extent similar to a fish oil diet. However, this percentage was lesser than the control (Figure 3A).

In addition, the recovery of bacteria from liver (Fritsche, 1997) and spleen (de Pablo, 2000a) was reduced at an early stage of infection in animals fed with an olive oil diet in comparison to values from an fish oil diet, suggesting that a reduction of immune system functions originates a immune state unable to efficiently eliminate L. monocytogenes (Figure 3B). Finally, bactericidal activity of peritoneal cells from animals fed a diet containing olive is more efficient than that from animals fed a diet containing fish oil (Puertollano, 2001b) (Figure 3C). Thus, the percentage of surviving bacteria was significantly reduced in the group fed an olive oil diet. In spite of the fact that the effects on the immune response appear to be more efficient in animals fed with an olive oil diet, the number of adhering bacteria as well as the number of invading bacteria was substantially larger in the group fed with an olive oil diet (Puertollano, 2002) (Figure 4).

Based on the results from the above mentioned studies, we can assert that olive oil plays a crucial role in reducing both inflammatory disorders and cancer risk, but the decrease of immune functions may lead to a loss of immune resistance, although the administration of diets containing fish oil are responsible for a dramatic diminution of survival percentage which indicates that $n-3$ PUFA are more immunosuppressive than olive oil.

As mentioned previously, the action of olive oil on immune system is due to oleic acid rather than other components of this fat. The administration of a diet containing olive oil in animals infected with $L$. monocytogenes and intraperitoneally treated with 

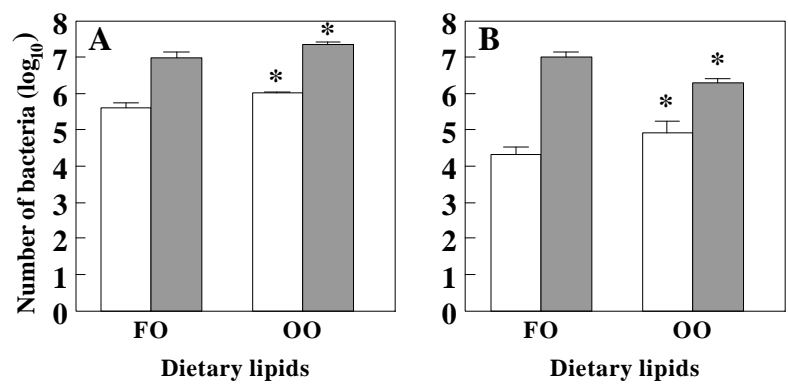

Figure 4

Determination of adhesion and invasion factors after infection of cells from mice fed for four weeks with a diet containing olive oil (OO) or a diet containing fish oil (FO) with a virulent strain of L. monocytogenes. Splenic cells were infected in vitro with $L$. monocytogenes for $2 \mathrm{~h}$ or $12 \mathrm{~h}$. A. Modification of adhesion factors in splenic cells cultured in the presence of L. monocytogenes. B. Modification of invasion factors in splenic cells cultured in the presence of $L$. monocytogenes. These figures have been partially adapted from Puertollano (2002). A value of ${ }^{*} p<0.05$ is considered as statistically significant.

$\mathrm{N}$-acetyl-L-cysteine (a precursor of the antioxidant gluthatione) had not effects on the survival of animals after infection or on the recovery of viable bacteria from spleen (Puertollano, 2003). It is possible that the immunosuppression exerted by diets containing olive oil and particularly fish oil diets is not modified by the administration of antioxidants.

\section{CLINICAL NUTRITION AND IMMUNE SYSTEM}

The interaction between fatty acids and immune system has increased the interest in the manipulation of fatty acid composition in lipid emulsions that have been used in clinical practice for over 30 years (see issue 8). The lipid emulsions most widely applied as nutritional support contain $n-6$ PUFA such as safflower oil or soybean oil, but they can have adverse effects on the immune system, especially when given in high doses over a short period of time. Thus, high levels of PUFA exert a suppressive effect on a number of immune functions (lymphocyte proliferation, cytokine synthesis or NK cell activity), which acquire a substantial importance because emulsions are often supplied to individuals who are at risk of sepsis. One study has reported that the addition of fish oil to nutritional supports based on soybean oil improved the survival and lymphocyte function in sepsis (Lanza-Jacoby, 2001), but other clinical observations have indicated that a high intake of essential fatty acids impairs synthesis of long-chain PUFA by inhibiting desaturation-elongation pathways. As a natural consequence, this event leads to an imbalanced synthesis of eicosanoids which affects many humoral and cellular immune functions
(Goodwin and Ceupens, 1983). Nevertheless, some beneficial effects have shown the application of emulsions containing olive oil as alternative of soybean oil for the use in parenteral nutrition because an olive oil-based lipid emulsion offers protective immunity and reduces inflammatory response (Moussa, 2000; Granato, 2000). In fact, with the purpose of finding a lipid emulsion capable of protecting mononuclear phagocyte system functions, a recent study revealed that the administration of a lipid emulsion enriched with olive oil to animals infected with Escherichia coli is an efficient method for it (Garnacho-Montero, 2002).

\section{OPEN QUESTIONS AND FUTURE PERSPECTIVES}

In recent years, evidence from a great number of investigations has indicated that fatty acids represent a crucial factor for the immune system, because they are able to modulate several of its functions. The integrated mechanisms responsible for the modulation of immune system by different fatty acids have not fully been elucidated. Nevertheless, it appears that the action of fatty acids on the production of eicosanoids, alteration of gene expression, formation of peroxides or changes in phospholipids composition promotes the modulation of immune functions. Besides, several studies show contradictory results and others are experimentally limited to animal models. Thus, it is important to note the lack of studies investigating the effects of dietary lipids on infectious disease resistance in humans. Therefore, it is currently important to determine the mechanisms involved in the modulation of immune system by olive oil, the action of oleic acid or other components of this fat on immune functions, the role that olive oil plays in the prevention and therapy of inflammatory diseases (particularly in rheumatoid arthritis) or in cancer risk, and finally, the participation of olive oil in the regulation of programmed cell death or apoptosis. According to the current knowledge, several mechanisms have been proposed, but different factors appear to participate in the regulation of immune system function by certain dietary lipids. In addition, the determination of the role that olive oil plays on the human immune system should be a crucial line of especial importance to immunonutrition. Therefore, future studies will provide new insights and increase the knowledge on the potential of olive oil as a nutrient exerting beneficial consequences for the immune system (in comparison with other fats). Thus, experimental and clinical investigations dedicated to olive oil represent an important opportunity that will contribute to advancing the knowledge on the action of olive oil in the health and diseases. 


\section{ACKNOWLEDGMENTS}

The authors would like to acknowledge to the Department of Education and Science (Group PAI CTS105, Autonomous Government of Andalusia, Spain), the Ministry of Education and Science (grant BSA-3648-2001) and the University of Jaén for supporting the present investigation. M.A. Puertollano receives a fellowship from the Department of Education and Science of the Autonomous Government of Andalusia (Teaching and Research Staff Training Program. Department of Education and Science. Autonomous Government of Andalusia, Spain).

\section{REFERENCES}

Abbas, A.K., Lichtman, A.H., Pober, J.S. (2001). Mecanismos efectores de las respuestas inmunitarias in inmunología celular y molecular. McGraw Hill-Interamericana pp. 241-352.

Anderson, M., Fritsche, K.L. (2002). (n-3) Fatty acids and infectious disease resistance. J. Nutr., 132, 3566-3576.

Bang, H.O., Dyerberg, J., Sinclair, H.M. (1980). The composition of the Eskimo food in north western Greenland. Am. J. Clin. Nutr., 33, 2657-2661.

Blok, W.L., Rabinovitch, M., Zilbelfarb, V., Netea, M.G., Buurman, W.A., van der Meer, J.W.M. (2002). The influence of dietary fish oil supplementation on cutaneous Leishmania amazonensis infection in mice. Cytokine, 19, 213-217.

Blot, W.J., Lanier, A., Fraumeni, Jr J.F., Bender, T.R. (1975). Cancer mortality among Alaskan natives, 1960-69. J. Natl. Cancer Inst., 55, 547-554.

Byleveld, M., Pang, G.T., Clancy, R.L., Roberts, D.K.C. (2000). Fish oil feeding enhances lymphocyte proliferation but impairs virus-specific $\mathrm{T}$ lymphocyte cytotoxicity in mice following challenge with influenza virus. Clin. Exp. Immunol., 119, 287-292.

Byleveld, M., Pang, G.T., Clancy, R.L., Roberts, D.K.C. (1999). Fish oil feeding delays influenza viru clearance and impairs production of interferon-gamma and virus-specific immunoglobulin $A$ in the lungs of mice. $J$. Nutr., 129, 328-335.

Calder, P.C., Yaqoob, P., Harvey, D.J., Watts, A., Newsholme, E.A. (1994). The incorporation of fatty acids by lymphocytes and the effect on fatty acid composition and membrane fluidity. Biochem. J., 300, 509-518.

Calder, P.C. (1998). Fat chance of immunomodulation. Immunol. Today, 19, 244-247.

Caygill, C.P., Charlett, A., Hill, M.J. (1996). Fat, fish, fish oil and cancer. Br. J. Cancer, 74, 159-164.

Chang, H.R., Dulloo A.G., Vladoiano, I.R., Piguet, P.F., Arsenijevic, D., Girardier, L., Pechere, J.C. (1992). Fish oil decreases natural resistance of mice to infection with Salmonella typhimurium. Metabolism, 41, 1-2.

Comstock, G.W., Ferebee, S.H., Hammes, L.M. (1967). A controlled trial of community wide isoniazid prophylaxis in Alaska. Am. Rev. Respir. Dis., 95, 935-943.

Connor, S.L., Connor, W.E. (1997). Are fish oil beneficial in the prevention and treatment of coronary artery disease?. Am. J. Clin. Nutr., 66, 1020S-1031S.

de Pablo, M.A., Ortega, E., Gallego, A.M., Alvarez, C., Pancorbo, P.L., Alvarez de Cienfuegos, G. (1998a). Influence of diets containing olive oil, sunflower oil or hydrogenated coconut oil on the immune response of mice. J. Clin. Biochem. Nutr., 25, 11-23.

de Pablo, M.A., Ortega, E., Gallego, A.M., Alvarez, C., Pancorbo, P.L., Alvarez de Cienfuegos, G. (1998b). The effect of dietary fatty acid manipulation on phagocytic activity and cytokine production by peritoneal cells from Balb/c mice. J. Nutr. Sci. Vitaminol., 44, 57-67.

de Pablo, M.A., Alvarez de Cienfuegos, G. (2000). Modulatory effects of dietary lipids on immune system functions. Immunol. Cell. Biol., 78, 31-39.

de Pablo, M.A., Puertollano, M.A., Gálvez, A., Ortega, E., Gaforio, J.J., Alvarez de Cienfuegos, G. (2000a). Determination of natural resistance of mice fed dietary lipids to experimental infection induced by Listeria monocytogenes. FEMS Immunol. Med. Microbiol., 27, 127-133.

de Pablo, M.A., Puertollano, M.A., Alvarez de Cienfuegos, G. (2000b). Immune cell functions, lipids and host natural resistance. FEMS Immunol. Med. Microbiol., 29, 323-328.

de Pablo, M.A.,, Ortega, E., Gallego, A.M., Alvarez, C., Alvarez de Cienfuegos, G. (2000c). Immunomodulation carried out by dietary fatty acids in experimental animals and humans. Grasas y Aceites, 51, 190-195.

de Pablo, M.A., Puertollano, M.A., Alvarez de Cienfuegos, G. (2002). Biological and clinical significance of lipids as modulators of immune system functions. Clin. Diagn. Lab. Immunol., 9, 945-950.

Filik, L., Ozyilkan, O. (2003). Olive-oil consumption and cancer risk. Eur. J. Clin. Nutr., 57, 191.

Fritsche, K.L., Shahbazian, L.M., Feng, C., Berg, J.N. (1997). Dietary fish oil reduces survival and impairs bacterial clearance in $\mathrm{C} 3 \mathrm{H} / \mathrm{Hen}$ mice challenged with Listeria monocytogenes. Clin. Sci., 92, 95-101.

Garnacho-Montero, J., Ortiz-Leyba, C. Garnacho-Montero, M.C., García-Garmendia, J.L., Pérez-Paredes, C., Moyano-Del Estad, M.R., Barrero-Almodóvar, A., Jiménez-Jiménez, F.J. (2002). Effects of three intravenous lipid emulsions on the survival and mononuclear phagocyte function of septic rats. Nutrition, 18, 751-754.

Goodwin, J., Ceupens, J. (1983). Regulation of the immune response by prostaglandins. J. Clin. Immunol., 3, 295-315.

Granato, D., Blum, S., Rössle, C., Le Boucher, J., Malnoe, A., Dutot, G. (2000). Effects of parenteral lipid emulsions with different fatty acid composition on immune cell functions in vitro. JPEN, 24, 113-118.

Harbige, L.S. (1998). Dietary $n-6$ and $n-3$ fatty acids in immunity and autoimmune disease. Proc. Nutr. Soc., 57, 555-562.

Hughes, D.A., Pinder, A.C. (2000). N-3 polyunsaturated fatty acids inhibit the antigen-presenting function of human monocytes. Am. J. Clin. Nutr., 71, 357S-360S.

James, M.J., Gibson, R.A., Neumann, M.A., Cleland, L.S. (1993). Effect of dietary supplementation with n-9 eicosatrienoic acid on leukotriene B4 synthesis in rats: a novel approach to inhibition of eicosanoid synthesis. J. Exp. Med., 178, 2261-2265.

Jeffery, N.M., Cortina, M., Newsholme, E.A., Calder, P.C. (1997a). Effects of variations in the proportions of saturated, monounsaturated and polyunsaturated fatty acids in the rat diet on spleen lymphocyte functions. $\mathrm{Br}$. J. Nutr., 77, 805-823.

Jeffery, N.M., Yaqoob, P., Newsholme, E.A., Calder, P.C. (1997b). The effects of olive oil upon rat serum lipid levels and lymphocyte functions are due to oleic acid. Ann. Nutr. Metab., 40, 71-80. 
Jump, D.B., Clarke, S.D. (1999). Regulation of gene expression by dietary fat. Annu. Rev. Nutr., 19, 63-90.

Kaplan, G.J., Fraser, R.I., Comstock, G.W. (1971). Tuberculosis in Alaska 1970. Am. Rev. Respir. Dis., 105, 920-926.

Klasing, K.C., Leshchinsky, T.V. (2000). Interactions between nutrition and immunity in Nutrition and Immunity, pp. 363-373. M.E. Gershwin, J.B. German y C.L. Keen, (Ed.). Humana Press Inc., Totowa.

Kremer, J., Lawrence, D.L., Jubiz, W., DiGiacomo, R., Rynes, R., Bartholomew, L.E., Sherman, M. (1990). Dietary fish oil and olive oil supplementation in patients with rheumatoid arthritis: clinical and immunologic effects. Arthritis Rheum., 33, 810-820.

Kromann, N., Green, A. (1980). Epidemiological studies in the Upernavik district, Greenland. Incidence of some chronic diseases 1950-1974. Acta Med. Scand., 208, 401-406.

Kromhout, D. (1989). N-3 fatty acids and coronary heart disease: epidemiology from Eskimos to Western populations. J. Intern. Med., 225, 47-51.

Lanza-Jacoby, S., Flynn, J.T., Miller, S. (2001). Parenteral supplementation with a fish-oil emulsion prolongs survival and improves rat lymphocyte function during sepsis. Nutrition, 17, 112-116.

Linos, A., Kaklamani, V.G., Kaklamani, E., Koumantaki, Y., Giziaki, E., Papazoglou, S., Mantzoros, C.S. (1999). Dietary factors in relation to rheumatoid arthritis: a role for olive oil and cooked vegetables?. Am. J. Clin. Nutr., 70, 1077-1082.

Linos, A., Kaklamanis, E., Kontomerkos, A., Koumantaki, Y., Gazi, S., Vaiopoulos, G., Tsokos, G.C., Kaklamanis, P. (1991). The effect of olive oil and fish consumption on rheumatoid arthritis: a case control study. Scand. J. Rheumatol., 20, 419-426.

Lipkin, M., Reddy, B., Newmark, H., Lamprecht, S.A. (1999). Dietary factors in human colorectal cancer. Annu. Rev. Nutr., 19, 545-586.

Llor, X., Pons, E., Roca, A., Alvarez, M., Mane, J., Fernandez-Banares, F., Gassull, M.A. (2003). The effects of fish oil, olive oil, oleic acid and linoleic acid on colorectal neoplastic processes. Clin. Nutr., 22, 71-79.

Martin-Moreno, J.M., Willett, W.C., Gorgojo, L. (1994). Dietary fat, olive intake and breast cancer risk. Int. J. Cancer, 58, 774-780.

Miles, E.A., Calder, P.C. (1998). Modulation of immune function by dietary fatty acids. Proc. Nutr. Soc., 57, 277-292.

Moussa, M., Le Boucher, J., García, J., Thaczok, J., Ragab, J., Dutot, G., Ohayon, E., Ghisolfi, J., Thouvenot, J.P. (2000). In vivo effects of olive oil-based lipid emulsion on lymphocyte activation in rats. Clin. Nutr., 19, 49-54.

Owen, R.W., Glacosa, A., Hull, W.E., Haubner, R., Wurtele, G., Spiegelhalder, B., Bartsch, H. (2000). Olive oil consumption and health: the possible role of antioxidants. Lancet Oncol., 1, 107-112.

Paul, K.P., Leichsenring, M., Pfisterer, M., Mayatepek, E., Wagner, D., Doman, M., Sonntag, H.G., Bremer, H.J. (1997). Influence of n-6 and n-3 polyunsaturated fatty acids on the resistance to experimental tuberculosis. Metabolism, 46, 619-624.

Puertollano, M.A., Algarra, I., Ortega, E., de Pablo, M.A., Alvarez de Cienfuegos, G. (2001a). Loss of cell natural killer cell activity after murine tumor transplantation appears as a consequence of dietary lipid administration. Anticancer Res., 21, 2697-2702.
Puertollano, M.A., de Pablo, M.A., Alvarez de Cienfuegos, G. (2001b). Immunomodulatory effects of dietary lipids alter host natural resistance of mice to Listeria monocytogenes infection. FEMS Immunol. Med. Microbiol., 32, 47-52.

Puertollano, M.A., de Pablo, M.A. (2002). Clinical application of fatty acids as modulating agents in immune functions. Rev. Clin. Esp., 202, 215-216.

Puertollano, M.A., de Pablo, M.A., Alvarez de Cienfuegos, G. (2002). Relevance of dietary lipids as modulators of immune functions in cells infected with Listeria monocytogenes. Clin. Diagn. Lab. Immunol., 9, 352-357.

Puertollano, M.A., de Pablo, M.A., Alvarez de Cienfuegos, G. (2003). Anti-oxidant properties of N-acetyl-Lcysteine do not improve the immune resistance of mice fed dietary lipids to Listeria monocytogenes infection. Clin. Nutr., 22, 313-319.

Risio, M., Lipkin, M., Newmark, H., Yang, K., Rossini, F.P., Steele, V. E., Boone, C.W., Kelloff, G.J. (1996). Apoptosis, cell replication, and Western-style diet-induced tumorigenesis in mouse colon. Cancer Res., 56, 4910-4916.

Rose, D.P., Connolly, J.M. (1999). Omega-3 fatty acids as cancer chemopreventive agents. Pharmacol. Ther., 83, 217-244.

Sanderson, P., Yaqoob, P., Calder, P.C. (1995). Effects of dietary lipid manipulation upon rat spleen lymphocyte functions and the expression of lymphocyte surface molecules. J. Nutr. Environ. Med., 5, 119-132.

Shapiro, A.C., Wu, D., Meydani, S.N. (1993). Eicosanoids derived from arachidonic and eicosapentaenoic acids inhibit T cell proliferative response. Prostaglandins, 45, 229-240.

Stubbs, C.D., Smith, A.D. (1984). The modification of mammalian membrane polyunsaturated fatty acid composition in relation to membrane fluidity and function. Biochim. Biophys. Acta, 779, 89-137.

Trichopoulou, A., Costacou, T., Bamia, C., Trichopopulos, D. (2003). Adherence to a Mediterranean diet and survival in a Greek population. N. Engl. J. Med., 348, 2599-2608.

Trichopoulou, A., Katsouyanni, K., Stuver, S., Tzala, L., Gnardellis, C., Rimm, E., Trichopoulos D. (1995). Consumption of olive oil and specific food groups in relation to breast cancer risk in Greece. J. Natl. Cancer Inst., 87, 110-116.

Yaqoob, P., Newsholme, E.A., Calder, P.C. (1994a). The effect of dietary lipid manipulation on rat lymphocyte subsets and proliferation. Immunology, 82, 603-610.

Yaqoob, P., Newsholme, E.A., Calder, P.C. (1994b). Inhibition of natural killer cell activity by dietary lipids. Immunol. Lett., 41, 241-247.

Yaqoob, P., Calder, P.C. (1995a). The effects of dietary lipid manipulation on the production of murine $T$ cell-derived cytokines. Cytokine, 7, 548-553.

Yaqoob, P., Calder, P. (1995b). Effects of dietary lipid manipulation upon inflammatory mediator production by murine macrophages. Cell. Immunol., 163, 120-128.

Yaqoob, P., Knapper, J.A., Webb, D.A., Williams, C.M., Newsholme, E.A., Calder, P.C. (1998). Effect of olive oil on immune function in middle-aged men. Am. J. Clin. Nutr., 67, 129-135.

Yaqoob, P. (2002). Monounsaturated fatty acids and immune function. Eur. J. Clin. Nutr., 56, S9-S13. 